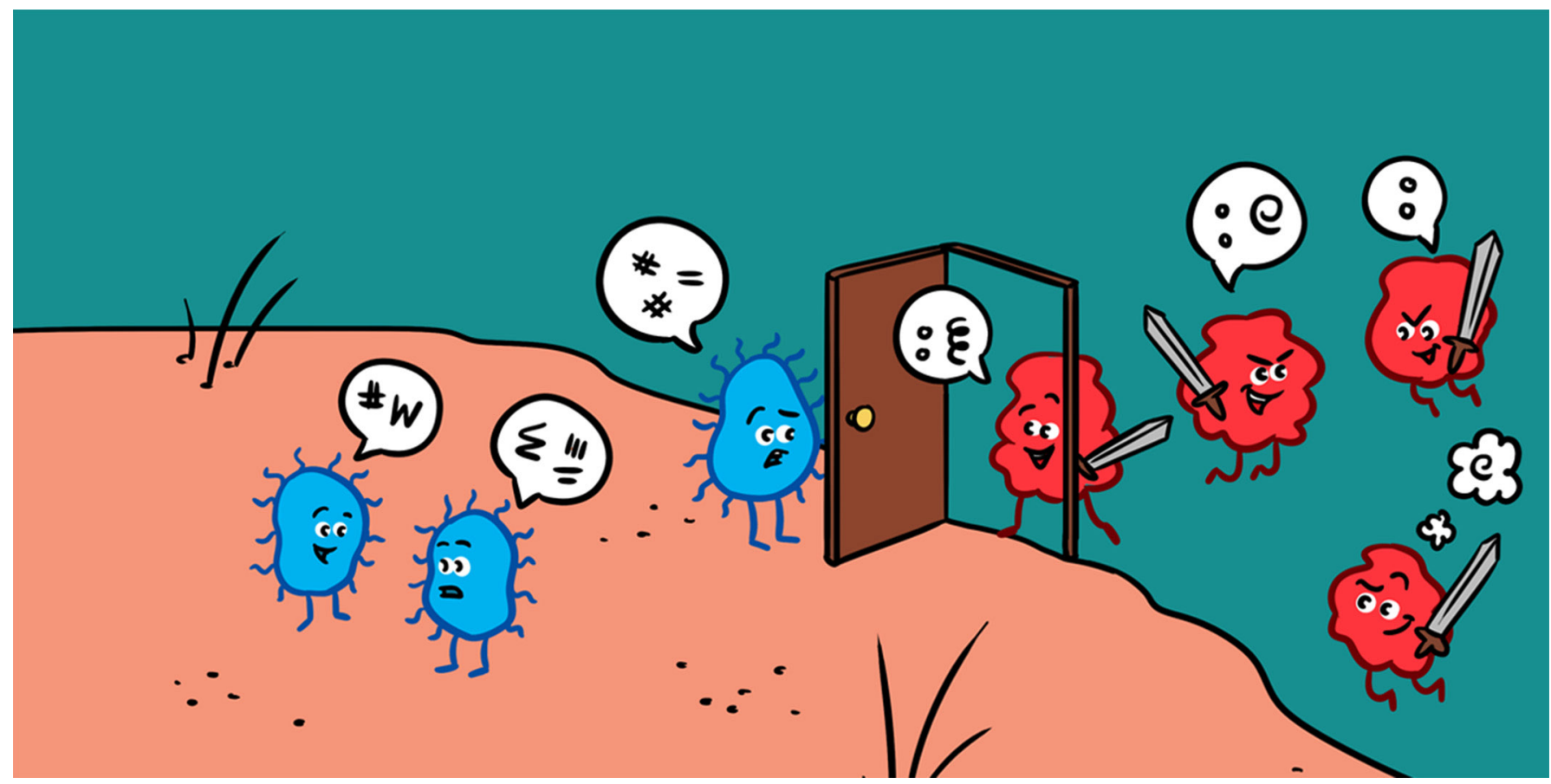

\title{
DO BACTERIA CHANGE THEIR LANGUAGE WHEN THEY ENTER THE BODY THROUGH WOUNDS? ANSWERS FROM BEDBUG EXPERIMENTS
}

\section{Oliver Otti ${ }^{1 *}$, Peter Deines ${ }^{2}$, Katrin Hammerschmidt ${ }^{3}$ and Klaus Reinhardt ${ }^{4}$}

${ }_{1}^{1}$ Animal Population Ecology, Animal Ecology I, University of Bayreuth, Bayreuth, Germany

2 Zoological Institute, Department of Biology, Christian Albrechts University Kiel, Kiel, Germany

3 Institute of Microbiology, Department of Biology, Christian Albrechts University Kiel, Kiel, Germany

${ }^{4}$ Applied Zoology, Department of Biology, Technische Universität Dresden, Dresden, Germany

YOUNG REVIEWERS:

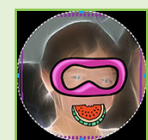

CELIA

AGE: 11

SHEIRDEN

AGE: 9
Bacteria live almost everywhere on earth, even within and outside animals, including insects and ourselves. Some bacteria help us digest our food, but others do harm and cause infections and illness. If we are injured, bacteria from the outside can enter our bodies through our wounds. The body will then fight against the incoming bacteria and this fight affects our own, useful bacteria in two ways. First, the fight harms both the incoming bacteria and our own helpful bacteria. Second, because the incoming bacteria may also be bad for the useful bacteria, our own bacteria might fight against the incoming ones. To do so, they use special molecules to talk to each other-a little bit like we use words. We studied the conversation of bacteria of the bedbug because it is an animal that is wounded very often. We wanted to understand how bacterial conversation changes when new bacteria 
MICROORGANISM OR MICROBE

A microscopic organism occurring either as a single cell or as a group of cells (colony).

\section{ENVIRONMENT}

The surrounding of a living being including all factors that affect its survival, development, and reproduction, such as temperature, humidity, food availability, predators, microorganisms, and availability of mating partners.

\section{MICROBIOME}

A collection of bacteria living together and interacting with each other in a defined space.

\section{Figure 1}

A simplified model of bacterial communication Quorum sensing is the scientific term for communication between bacteria. Bacteria can either talk to other bacteria or interfere with each other's talk by muting other bacteria or by reducing other bacteria's growth.

enter the animal's body. We found that females had different species of bacteria before they were wounded compared with after they were wounded. We also found that the bacteria communicated differently after the females were wounded. Our study helps people to understand how an animal's response to wounds and the communication of the bacteria in that animal work together.

\section{INTRODUCTION}

All organisms, including animals, live in close relationships with bacteria. Bacteria can live on any surface of the animal, residing within or between its cells. Some bacteria can only be found in specific organ systems, like light-producing bacteria in the light organ of bobtail squids or the bacteria in the cow stomach. The community of bacteria and other microorganisms or microbes (microscopic organisms) that live in a particular environment, such as inside an animal, is called a microbiome. When we talk about an animal (called the host) and its associated microbiome, we call it a metaorganism [1]. Scientists have realized that it is important to study how microbiomes affect the health and reproduction of hosts.

Many interactions with bacteria from the environment happen on the host's skin. When the skin is damaged by an injury, bacteria from the environment might enter the wound and spread inside of the host organism. In some species, wounding happens regularly, such as during fighting. In other animals, wounds occur during mating. Bacteria also live on male and female reproductive organs and can be transferred between the mating partners. This is true for many animal species, such quorum sensing
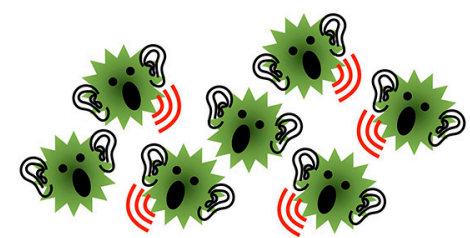

Bacteria interfere with each other's talk quorum sensing inhibition
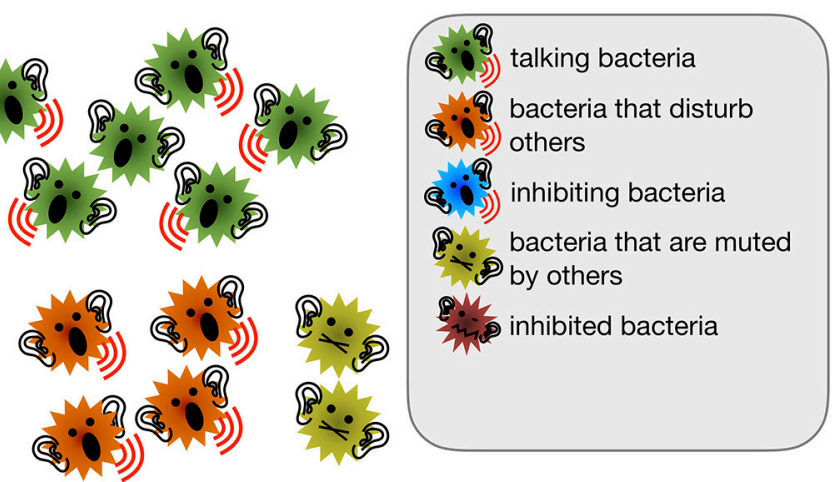

Bacteria inhibit each other growth inhibition

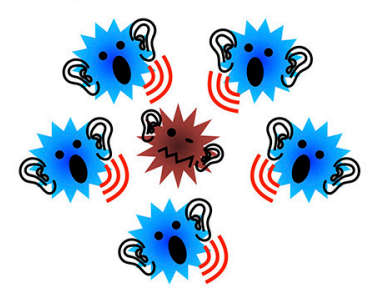




\section{HOST}

An organism harboring another organism (symbiont). This "guest" is being provided with nourishment and shelter. If the host is robbed of nourishment and harmed by the guest, then we speak of a parasite. If the host gets something in return (rare nutrient, protection), the guest is called a mutualist. If the host does not get anything in return and does not suffer from the guest, it is called a commensal.

\section{METAORGANISM}

The host organism and all of its associated microbes.

\section{QUORUM SENSING}

Quorum sensing is the scientific term for communication between bacteria. Bacteria can either talk to other bacteria or interfere with each other's talk by muting other bacteria or by reducing other bacteria's growth. as insects, birds, and humans [2]. How animals prepare themselves for bacterial attacks after mating and how the host's microbiome behaves toward the bacterial invaders is still largely unknown. In some metaorganisms, the local microbiome helps the host by fighting the invading bacteria. The bacteria of the local microbiome do this by talking with each other (called quorum sensing) and by stopping the communication of the invading species (Figure 1). We know that this communication helps to maintain both the stability of the microbial community and the stability of the entire metaorganism [1]. However, we do not know much about how this communication between the microbiome and the invading bacteria happens.

\section{WHY DO BACTERIA COMMUNICATE?}

As we said above, bacteria can communicate with their own kind and also with different kinds of bacteria [3]. The communication can help to control the number of bacteria living in the surrounding environment. It can also help to get information about the number of bacteria, which is important if nutrients are low, or if the bacteria are competing for the same nutrients. However, it is not only the host's bacteria that communicate; the invading bacteria can do so, too. For example, invading bacteria communicate when they act together during infections. This communication can help invading bacteria avoid the immune response of the host and can improve the invaders' chances of infecting the host. Finally, both the host bacteria and the invading bacteria can disturb each other's communication and can stop each other from growing.

\section{CAN THE HOST TALK BACK TO ITS BACTERIA?}

Making things even more interesting, the host itself can interact with the invading bacteria. Because bacterial attacks can be very bad for hosts, hosts can disturb bacterial communication to reduce how quickly information spreads among infecting bacteria, or to disturb bacterial growth in order to prevent infection. For example, hosts can increase the temperature, the acidity or even the stickiness of the tissue where bacteria are living, to reduce the ability of the bacteria to grow.

We do not know much about these two forms of bacterial communication yet-communication between bacteria themselves and between the microbiome and the host. The experiments we will tell you about here take the first step in that direction: in the bedbug, which experiences regularly wounding, we examined the bacterial side of communication, before and after such host wounding. 


\section{PARAMERE}

A part of the external reproductive organ of male insects. In bedbugs this external part forms a needle-like mating organ with which the male bedbug stings the female (cuts her skin) every time they mate.

\section{MESOSPERMALEGE}

An organ unique to the bedbug family. Bedbug females have evolved this immune organ in response to the mating stings by the males. This organ is filled with immune cells and helps females to live longer.

\section{HOW DO BEDBUG MALES WOUND FEMALES DURING MATING?}

The common bedbug is about $5 \mathrm{~mm}$ long, brown and looks a bit like half a lentil. It hides in cracks and hollow spaces of beds or bedroom walls, as it likes to feed on human blood. Every now and then bedbugs come out at night and feed by sucking blood from a sleeping human. Bedbugs need six such bloodmeals to become adults. The male bedbug has a needle-like mating organ (called the paramere) with which it stings the female (cuts her skin and makes a wound) every time they mate [4] (Figures 2A,B, 3). This mating behavior is called traumatic insemination. It sounds bizarre, but it is actually found in quite a few animals [5]. Bacteria have been found on the male's paramere and can be transferred to the female. Sometimes, this causes the female bedbugs to die $[6,7]$. In response, females have evolved an immune organ called the mesospermalege. This organ is filled with immune cells and helps females to live longer, despite the bacteria. One difficulty for our experiment was that female bedbugs often mate after they have fed-therefore, we needed to come up with an idea to make sure we only looked at the effects of wounding, not of feeding.

We had three objectives for our experiments: (1) to identify the bacteria living on the reproductive organs of the bedbug; (2) to study how wounding and feeding affects the microbiome of female bedbugs; and (3) to figure out if the bacteria in the bedbug's microbiome can communicate with each other.

\section{MICROBIAL COMMUNITIES OF FEMALE BEDBUGS CHANGE AFTER WOUNDING}

We studied the bacteria of eight different bedbug populations by culturing them in Petri dishes (little plates filled with solid food for bacteria to grow on) (Figure 2A). We identified all the bacteria from the environment of the bedbug, and also from the skin of males and females, the male paramere, the female blood, and the mesospermalege (Figure 2A). We also compared mated females with females that had never mated, so that we could look separately at the effect that feeding and wounding had on the microbiome.

In total, we found twenty different bacterial species. We found 10 in the bedbug environment, 11 in female organs and only two on the male paramere. Some species were found in more than one location. The number and type of bacteria was different between mated and non-mated individuals, between fed and non-fed females and 
Figure 2

A simplified outline of our study and questions we aimed to answer.

(A) Steps 1-3 show how we determined the names of the bacterial species found in specific organs. First we mated and/or fed females and males.

Then, we removed the paramere from the males and the

mesospermalege from the females. We also removed some blood with a tiny syringe. We grew the bacteria from these samples on Petri dishes and once the bacteria had grown, we selected them and identified the species names of the different bacteria we found. (B) Steps 4 and 5 show how we measured the ability of bedbug

bacteria to

communicate or to disturb other bacteria's communication. To do this, we used Petri dishes with special test bacteria that could change color

depending on the type of bacterial

communication that was happening. If, after $24 \mathrm{~h}$ of growth, no colored zones formed around the bacteria this meant that the bedbug bacteria were not able to

communicate with the test bacteria. A purple zone showed us that the bedbug bacteria were able to talk. A milky white zone showed us that the added bedbug bacteria were able to disturb other bacteria's communication

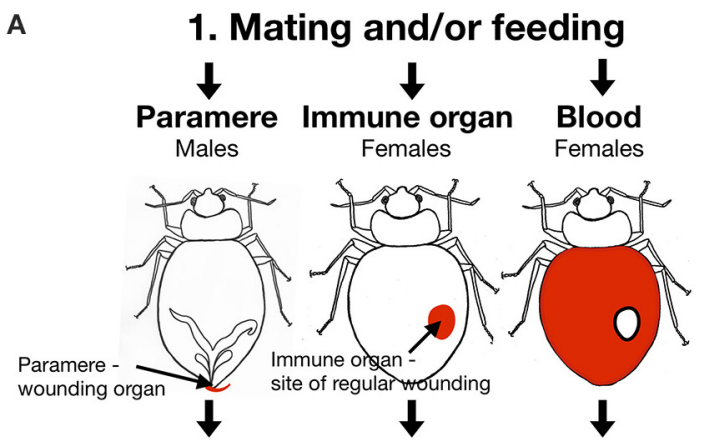

2. Growing bacteria in petri dishes

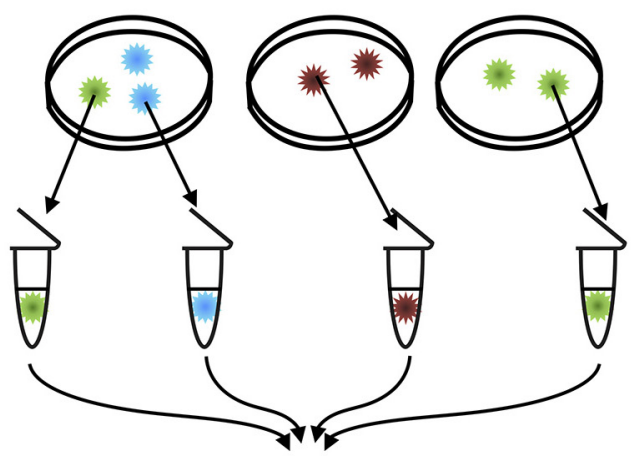

3. Identification of bacteria species names

B

4. Do bacteria talk?

Bedbug bacteria
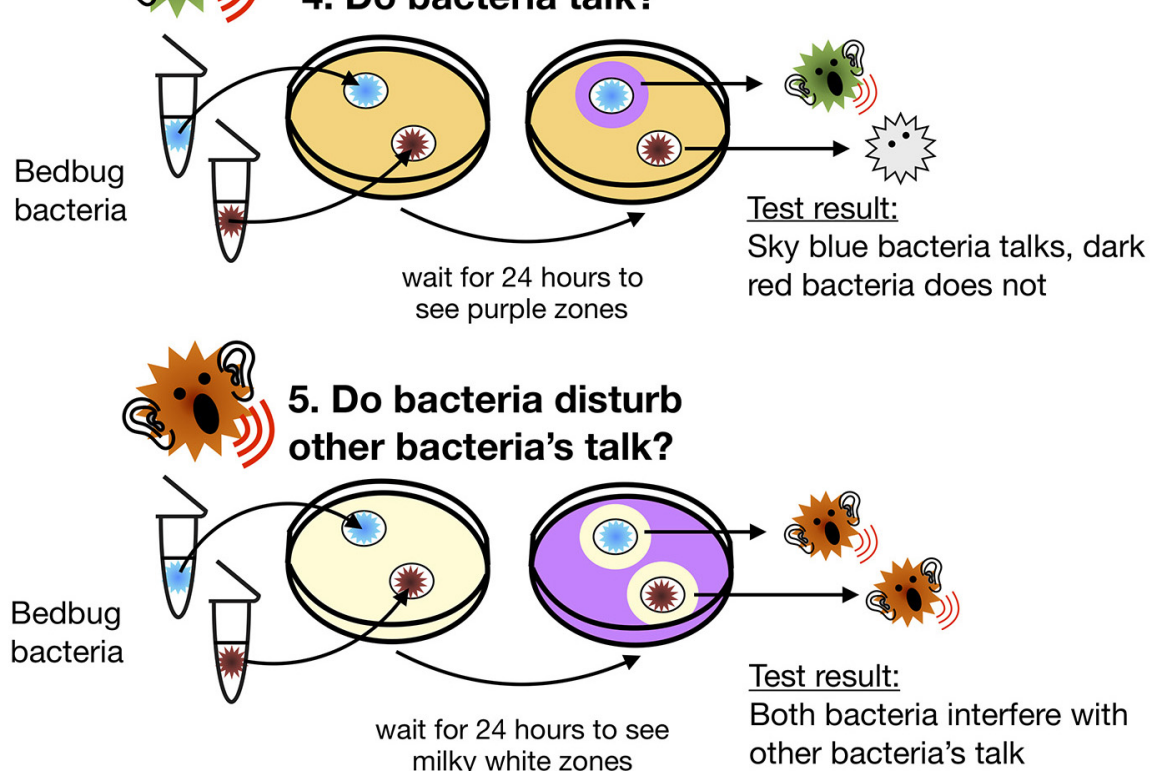

Figure 2

between organs. Only $30 \%$ of mated females had bacteria in their mesospermalege, while $62 \%$ of females that had not mated had bacteria there. We saw the same pattern in the blood $20 \%$ of mated females and $31 \%$ of non-mated females had bacteria). The number of bacterial 
species was higher for females that had mated compared with nonmated females ( 7 vs. 3 species). Females that had fed were also more likely to have bacteria ( 7 of 8 females) than unfed ones ( 3 of 8 females). No bacteria were found in females that were mated but unfed. Some of these results were a little surprising to us, but our findings that males and females carry different microbiomes agrees with findings in many other species, such as humans, mice, and mosquitoes. Finding fewer bacteria in the mesospermalege after mating suggests that this female organ might play a central role in the control of bacteria by the female's immune system.

\section{BACTERIA FROM REPRODUCTIVE ORGANS OF BEDBUGS CAN COMMUNICATE AND STOP OTHER BACTERIA FROM COMMUNICATING}

In order to find out whether these bacteria could communicate and stop others from communicating (Figure 2B), we conducted two tests. In the first test, we grew the bacteria on a special food that would turn purple if the bacteria collected from the bedbug organs produced the molecules needed to communicate. In the second test, we used another food that would turn milky white if the bacteria stopped the signal molecules of other bacteria (Figure 2B).

More than half of the bacterial species were able to communicate and about three quarters (72\%) were able to stop other bacteria from communicating. Half of the bacterial species were even able to stop the growth of other bacteria. Although stopping the growth of other bacteria is not really communication, bacteria that can do this dramatically increase their possibility of surviving and getting nutrients.

Most of the reproductive organs we looked at carried bacteria that could both communicate and stop others from communicating (Figure 4). However, none of the bacterial species from the blood of mated females were able to communicate, but about half of the bacteria in mesospermalege of mated females were able to communicate and to stop others from communicating. We found the opposite in non-mated females: bacteria were able to communicate and stop others from communicating in the blood, but not in the mesospermalege (Figure 4). We do not know for sure, but our findings suggest that bacterial communication might be different on different organs and between females that have recently mated and those who have not mated. 
Figure 3

A representation of the study design with the four groups of females from which we collected bacteria. Fed and unfed mated individuals are on the right and fed and unfed non-mated individuals are on the left. Males have a mating organ shaped like a needle. With this needle males pierce females into the belly and transfer the sperm to the female. This is called traumatic insemination. Females cannot defend themselves against such a mating, especially not when they just fed (top right in the figure)

\section{Figure 4}

Bacteria found in bedbugs change their communication behavior depending on which organ they were found in. The names of some of the bacterial species that we found are listed in the right-hand column. You can see that both Staphylococcus epidermidis and Staphylococcus pasteuri were found in male and female organs, whereas the other bacteria were only found in females. You can also see that bacterial

communication differed between organs and males and females.

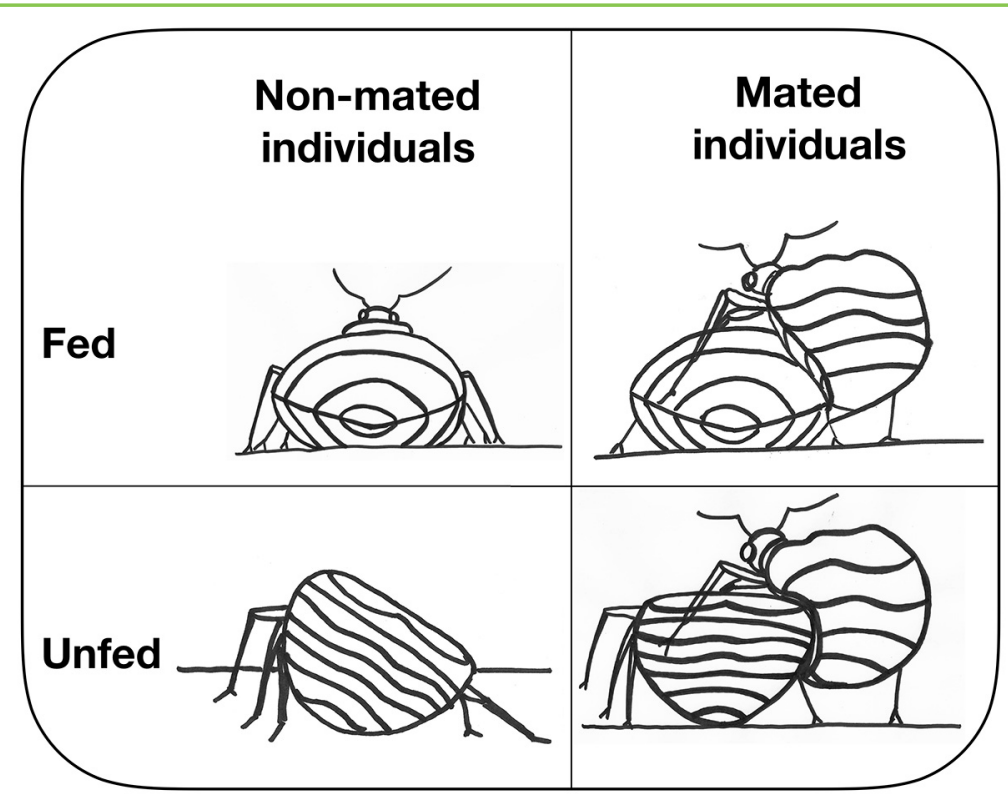

Figure 3

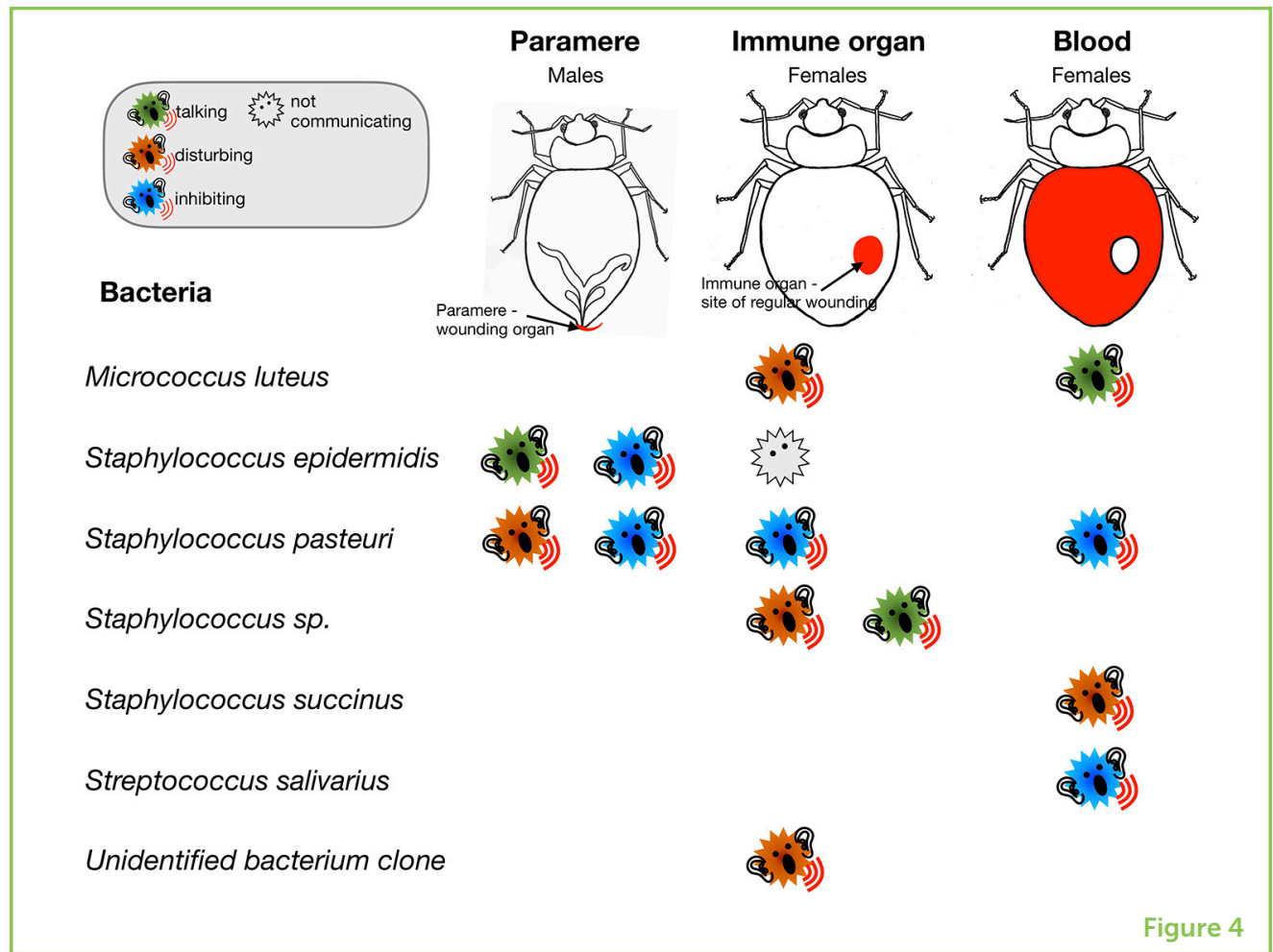

\section{WHAT DID WE LEARN ABOUT BEDBUGS AND THEIR BACTERIA?}

The microbiome is an essential component of every animal, including bedbugs. It undergoes certain changes due to the wounding that occurs during mating. We showed that the differences between males and females, as well as the bedbug feeding and mating behaviors, strongly 
affect the mix of bacterial species in the microbiome and the ability of those bacteria to communicate. Our findings looked at one side of the quorum sensing communication-that of bacteria. Future work could test whether quorum sensing can also be carried out by the host cells. Generally, bedbugs might be a good system for studying how quorum sensing communication works in a natural system.

\section{AUTHOR CONTRIBUTIONS}

$\mathrm{OO}$ prepared a first draft of the manuscript. PD and $\mathrm{KH}$ wrote the sections on bacterial communication. $\mathrm{OO}$ and KR wrote the sections on bedbug biology, host-pathogen interactions and the results of the study. OO prepared the figures. All authors contributed to each section by reviewing each other's writing.

\section{ACKNOWLEDGMENTS}

We thank Lina Emmy Kempke and Minna Hayter, two 12 years-old students from Dresden and Sheffield, for their valuable comments on the last draft of our manuscript, especially also for weeding out the jargon and improving the glossary.

\section{ORIGINAL SOURCE ARTICLE}

Otti, O., Deines, P., Hammerschmidt, K., and Reinhardt, K. 2017. Regular wounding in a natural system: bacteria associated with reproductive organs of bedbugs and their quorum sensing abilities. Front. Immunol. 8:1855. doi: 10.3389/fimmu.2017.01855

\section{REFERENCES}

1. Bosch, T. C. G., and McFall-Ngai, M. J. 2011. Metaorganisms as the new frontier. Zoology 114:185-90. doi: 10.1016/j.zool.2011.04.001

2. Lockhart, A. B., Thrall, P. H., and Antonovics, J. 1996. Sexually transmitted diseases in animals: ecological and evolutionary implications. Biol. Rev. 71:415-71. doi: 10.1111/j.1469-185X.1996.tb01281.x

3. Waters, C. M., and Bassler, B. L. 2005. Quorum sensing: cell-to-cell communication in bacteria. Ann. Rev. Cell Dev. Biol. 21:319-46. doi: 10.1146/ annurev.cellbio.21.012704.131001

4. Reinhardt, K., and Siva-Jothy, M. T. 2007. Biology of the bed bugs (Cimicidae). Ann. Rev. Entomol. 52:351-74. doi: 10.1146/annurev.ento.52.040306.133913

5. Reinhardt, K., Anthes, N., and Lange, R. 2015. Copulatory wounding and traumatic insemination. Cold Spring Harb. Perspect. Biol. 7:a017582. doi: 10.1101/cshperspect.a017582 
6. Otti, O., McTighe, A. P., and Reinhardt, K. 2013. In vitro antimicrobial sperm protection by an ejaculate-like substance. Funct. Ecol. 27:219-26. doi: 10.1111/1365-2435.12025

7. Reinhardt, K., Naylor, R. A., and Siva-Jothy, M. T. 2005. Potential sexual transmission of environmental microbes in a traumatically inseminating insect. Ecol. Entomol. 30:607-11. doi: 10.1111/j.0307-6946.2005.00730.x

SUBMITTED: 30 May 2018; ACCEPTED: 03 January 2019; PUBLISHED ONLINE: 28 January 2019.

EDITED BY: Michele A. Johnson, Trinity University, United States

CITATION: Otti O, Deines P, Hammerschmidt K and Reinhardt K (2019) Do Bacteria Change Their Language When They Enter the Body Through Wounds? Answers From Bedbug Experiments. Front. Young Minds 7:1. doi: 10.3389/frym.2019.00001

CONFLICT OF INTEREST STATEMENT: The authors declare that the research was conducted in the absence of any commercial or financial relationships that could be construed as a potential conflict of interest.

COPYRIGHT () 2019 Otti, Deines, Hammerschmidt and Reinhardt. This is an openaccess article distributed under the terms of the Creative Commons Attribution License (CC BY). The use, distribution or reproduction in other forums is permitted, provided the original author(s) and the copyright owner(s) are credited and that the original publication in this journal is cited, in accordance with accepted academic practice. No use, distribution or reproduction is permitted which does not comply with these terms.

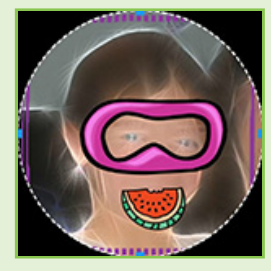

\section{YOUNG REVIEWERS}

\section{CELIA, AGE: 11}

I love to swim, I love the color purple, and also love science. I have dyed my hair purple, and just cut my hair really short. I have two pets, a dog named Marco and a cat named Polo. They are the cutest pair. My favorite kind of ice cream is mint chip. I also love cooking. I am also a girl scout and my favorite girl scout cookie is thin mints.

\section{SHEIRDEN, AGE: 9}

I am a fourth grade student. My favourite subject is reading. My least favourite subject is math. I have a brown belt in karate. I have a little brother. I love going on my trampoline and play games. 

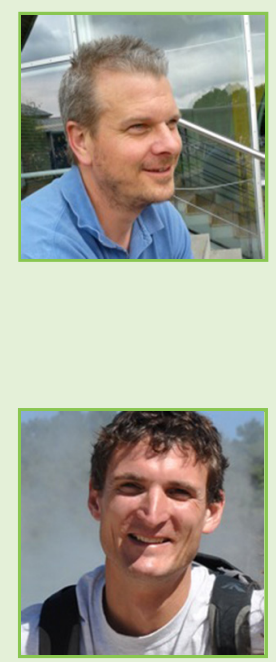

\section{AUTHORS}

\section{OLIVER OTTI}

I am an evolutionary biologist currently working at the University of Bayreuth in Germany. My research looks at how reproduction and immunity are connected. I do this by combining studies on host-parasite interactions and on the conflict between males and females. I am also interested in how ants and bumblebees use their venom to defend themselves from microbes. When I am not working, I like to spend my time with my family or go bird watching. *oliver.otti@uni-bayreuth.de

\section{PETER DEINES}

I am a microbial ecologist at the University of Kiel, Germany. My research explores the different interactions between hosts and microbes, which include predator-prey, hostpathogen, and symbiosis. Currently, I study the ecological and evolutionary dynamics of microbes in microbiomes and the interactions between microbiome members.

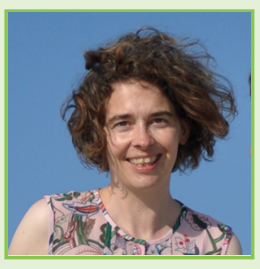

\section{KATRIN HAMMERSCHMIDT}

I am an evolutionary biologist, working at the University of Kiel in Germany. Currently, I am mainly studying the evolutionary origins of multicellularity, which means the transition from single-celled organisms to organisms that are composed of multiple cells, such as animals, plants and other complex life forms. As all known transitions are ancient and thus difficult to research, I use single-celled bacteria to evolve simple multicellularity in the laboratory.

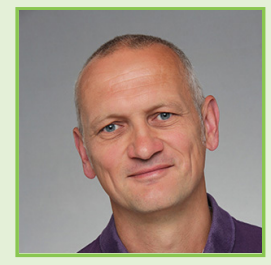

\section{KLAUS REINHARDT}

I am a professor of applied zoology at the Technical University of Dresden in Germany. I study sperm biology, the evolution of new species, and the conflict between males and females in insects. I think that it is important to understand how reproduction works, because it gives us insight into the evolution of the different reproductive tactics found in males and females. The study of reproduction can also help us better understand how species evolve. 